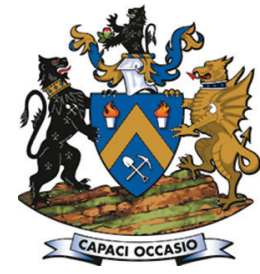

Affiliation:

1 Worley, South Africa.

Correspondence to:

K. Balt

Email:

kbalt@mweb.co.za

Dates:

Received: 18 Dec. 2019

Revised: 30 Jul. 2020

Accepted: 30 Jul. 2020

Published: August 2020

How to cite:

Balt, K. and Goosen, R.L.

MSAHP: An approcah to mining

method selection.

The Southern African Institute of

Mining and Metallurgy

DOI ID:

http://dx.doi.org/10.17159/2411

9717/1072/2020

\title{
MSAHP: An approach to mining method selection
}

\author{
K. Balt ${ }^{1}$ and R.L. Goosen ${ }^{1}$
}

\begin{abstract}
Synopsis
Mining method selection is the most fundamental activity of a mining study, because everything else depends on it. It is a process whereby the mining method attributes are matched to the orebody characteristics. This crucial decision must invariably be made at a stage of the study when the least information is available.

Method selection with Analytic Hierarchy Process (MSAHP) is based on the Analytic Hierarchy Process (AHP) and was developed in Microsoft Excel ${ }^{\mathrm{TM}}$. It was designed to facilitate good decisions based on expert judgement and sparse data according to a systematic mathematical process. The program matches the attributes of 10 mining methods to the characteristics of the orebody under review and results in the ranking of the mining methods according to their suitability to the orebody.

The underlying premise of MSAHP is that the mining method best suited to the orebody will also be the most economical.
\end{abstract}

\section{Keywords}

mining method selection, orebody characteristics, Analytic Hierarchy Process.

\section{Introduction}

Mining method selection is a process whereby the mining method attributes are matched to the orebody characteristics. The mining method whose attributes most closely match the orebody characteristics is the one with the highest potential for successful extraction and, by implication, should result in the best business case.

This tool, developed in Microsoft Excel ${ }^{\mathrm{TM}}$ and based on the Analytic Hierarchy Process (AHP), is named Method Selection with AHP (MSAHP). The tool prompts the user for both numeric and linguistic descriptions of the orebody characteristics based on the information available at the time of the analysis. During the process, the descriptions are quantified according to assigned discreet values. In parallel, the mining method attributes are compared to each other, pairwise fashion, with respect to each orebody characteristic, and the relative suitability of the mining method attributes to the orebody is quantified through AHP. Finally, the two parts of the analysis are synthesized, and this results in the ranking of the mining methods according to the suitability of each to the orebody in question.

\section{Objective}

The objective of this work was to simplify the mining method selection process, while at the same time modernizing the technology, to facilitate quick decisions, based on minimal information, in the early phases of mining studies.

\section{Scope}

The underlying premise of MSAHP is that the mining method best suited to the orebody will also be the most economical. It is stressed that MSAHP is not a substitute for any economic model. Its primary use is to identify mining methods with attributes that most closely match the orebody characteristics and, consequently, to inform the mining engineer on the mining methods that need to be focused on for subsequent study phases and more robust technical, economic, and financial models tuned to those mining methods.

MSAHP is primarily intended for application to underground, hard-rock mining methods; however, open-pit mining is included because of its versatility and its widespread application to shallow orebodies. 


\section{MSAHP: An approach to mining method selection}

Mining methods specific to underground soft rock, such as coal and salt, were not considered per se, but the principles are the same. It should be noted that longwall stoping in this work refers to long (about $30 \mathrm{~m}$ ), narrow, and normally flat-dipping panels in hard rock; and not to the widespread longwall mining method as understood in the context of coal mining.

Mining methods which have become largely redundant, like shrinkage stoping and top slicing, have been excluded from consideration because they are now rarely applied.

Controllable factors, such as mining factors and mining costs, are included in MSAHP to facilitate the selection if the technical ranking is very close.

MSAHP is intended to facilitate the mining method selection process and not to select the mining method. This is the task of the skilful and experienced mining engineers who will use MSAHP to verify and justify their selection rather than to make the selection.

\section{Importance of mining method selection}

Mining method selection is the most fundamental activity in a mining study because everything else depends on it. The mine design and scheduling cannot be established before the mining methods are decided upon. Equally, if the choice of mining methods changes after mine design and scheduling have commenced, significant and costly delays and overruns on the project plan and schedule are inevitable.

This crucial decision must invariably be made at a stage of the study phases when the least information is available. The MSAHP was designed to facilitate good decisions based on expert judgement according to a transparent process, to complement quantified parameters.

\section{History of mining method selection}

The problem of selecting the appropriate mining method has been grappled with for decades. The first pioneer to devise a numerical approach was David E. Nicholas in the early 1980s (Nicholas, 1981). Nicholas' approach has been used ever since, with some modification by the University of British Columbia who devised an online tool that allows for interactive input and feedback. Statistics on how often these tools have been used have not been researched.

Nicholas approached the selection process in two stages. In Stage 1, those mining methods which should be considered in greater detail are identified based on the orebody geometry, grade distribution, and geomechanical properties of the orebody and host rock. In Stage 2, costs, production rate, labour, and other mining factors are selected from among the mining methods identified in Stage 1.

Nicholas' method is fairly robust and appears to have been widely applied in the industry. However, it does have shortcomings, some of which are highlighted below.

\section{Dated mining methods}

In modern day mining the general shape of the orebody seems to be referred to as either massive or stratiform, and the notion of an irregular orebody seems to be rarely used. The definition of the equidimensional shape fits the modern-day nomenclature of 'massive', while 'stratiform' is equivalent to 'platy' and 'tabular' refers specifically to near-horizontal stratiform orebodies. Some of the mining methods that were used widely in Nicholas' time, such as shrinkage-stoping and top-slicing, British spelling are now seldomly practiced commercially.

\section{Resolution}

The parameter ranges in this scheme are coarse. For example, an orebody thickness of $10 \mathrm{~m}$ or less is deemed narrow; however, a mining method suitable for a $1.5 \mathrm{~m}$ thick, flat-dipping orebody is different from one that is suitable for $9 \mathrm{~m}$ thickness. Equally, the range for intermediate dip is $20^{\circ}$ to $55^{\circ}$, but a mining method suitable for $25^{\circ}$ dip is different from one that would be considered for a $43^{\circ}$ dip.

\section{Bias}

In the Nicholas method the emphasis automatically placed on the geomechanical properties of the rock mass introduces unnecessary bias because the rock mechanics parameters for the hangingwall, ore, and footwall are summed. Thus, the geomechanical properties are assigned a weight three times that of any of the other parameters, making this the single most important selection criterion. In practice the rock mechanics considerations guide the layout and design of the chosen mining method, but they seldomly decide the mining method.

\section{Insufficient differentiation}

In the Nicholas method, all the parameters considered carry the same weight, regardless of the relative importance of the individual parameters. For example, two mining methods might be suitable to a thin orebody; however, one might be more suitable to a steep dip and the other to a flat dip. Nicholas' method does not allow for this type of prioritization.

\section{Concise introduction to AHP}

In the early 1980s, Thomas L Saaty introduced the AHP. The following, most concise definition of the AHP, is given by Saaty: 'The Analytic Hierarchy Process (AHP) is a theory of measurement through pairwise comparisons and relies on the judgements of experts to derive priority scales. It is these scales that measure intangibles in relative terms. The comparisons are made using a scale of absolute judgements that represents, how much more, one element dominates another with respect to a given attribute. The judgements may be inconsistent, and how to measure inconsistency and improve the judgements, when possible to obtain better consistency is a concern of the AHP. The derived priority scales are synthesised by multiplying them by the priority of their parent nodes and adding for all such nodes' (Saaty, 2008, p. 83)

This definition is illustrated in Figure 1.

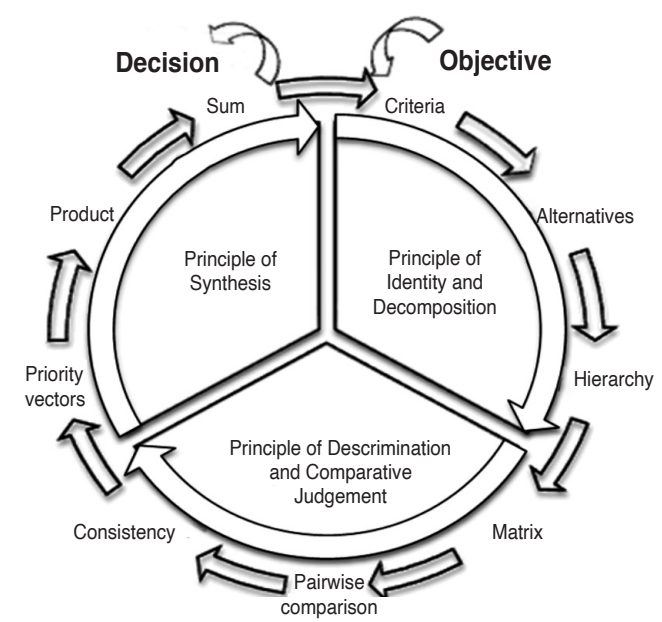

Figure 1-The AHP wheel after Balt (2016) 


\section{MSAHP: An approach to mining method selection}

For MSAHP, the actual orebody characteristics are assigned weights based on linguistic descriptions such as 'very deep', 'steeply inclined', 'poor', 'uniform' etc., but also, where appropriate, actual values. In parallel, the mining method attributes are compared to each other in pairwise fashion with respect to each characteristic. Finally, a vector is determined that ranks the mining methods in order of suitability to the orebody.

\section{Literature review}

Many papers have been published that deal with the application of AHP to mining engineering problems in general, and specifically to the aspect of selecting the most suitable mining method.

Ataei et al. (2008) conducted a survey among 17 experts that were involved in the mine planning and design process. They identified 13 criteria and assessed their relative importance through pairwise comparisons with respect to each evaluated mining method to determine priority vectors. The six considered mining methods were ranked in order of suitability to the characteristics of an orebody in Northern Iran. Their conclusion was that cut-and-fill was the most appropriate mining method for that mine. The most important selection criteria were the orebody thickness, rock mechanics factors, and dip of the orebody.

Musingwini and Minnitt (2008) used AHP to rank several mining methods as practised in the platinum fields of the Bushveld Complex in South Africa in order of efficiency. Efficiency criteria were identified, and by drawing on the knowledge and experience of mine technical services and project management practitioners in the industry, the relative importance of each criterion was determined. They found that conventional mining (longwall mining with pillars on dip or strike and scraper cleaning) was the most efficient. Important conclusions that were drawn include identification of the use of AHP in optimization, production performance, and personnel career path development.

Balt (2016) identified a need in the mining industry for a practical guideline to help engineers carry out AHP in any discipline where a choice must be made between multiple alternatives. based on multiple selection criteria. Kluge and Malan (2011) investigated the application of AHP to mining engineering problems, and Yavuz, Iphar, and Once (2008) used AHP to determine the optimum support for a haul road in a colliery.

The above review demonstrates that the AHP is an acceptable decision-making tool for mining applications.

During the early phases of feasibility studies, simplicity with a degree of uncertainty is better than complexity, which necessarily increases uncertainty in the face of sparse data.

\section{Mining methods}

Nicholas (1981) rightly observed that: '... no one mining method is so restrictive that it can be used for only one set of characteristics...' . In most analyses the geometry of the orebody necessitates more than one mining method, or hybrid methods that combine the attributes of compatible mining methods. Many variations, combinations, and hybrid systems are employed, and widely varying naming conventions exist. However, only a few basic mining methods are actively employed in the world today. For MSAHP, 10 of these are considered. They are listed in Table I together with concise definitions of each.

\section{Orebody characteristics}

The essential orebody characteristics for mining method selection were condensed from various sources, including Hustrulid and Bullock (2001), Brady and Brown (2006), Nicholas (1981), and other publications and papers available on the topic.

\section{Table I}

\section{Definitions of mining methods as applied to the selection tool}

\begin{tabular}{|c|c|c|}
\hline Method & Abbreviation & Definition \\
\hline Open pit & OPM & A surface mining method for shallow, flat-dipping orebodies that progresses deeper by mechanical means. \\
\hline Block cave & $\mathrm{BCM}$ & $\begin{array}{l}\text { An underground mining method for flat-dipping, thick orebodies that progresses upwards by means of self-sustaining cave propagation } \\
\text { of the ore. }\end{array}$ \\
\hline Sublevel caving & SLC & $\begin{array}{l}\text { An underground mining method for steep-dipping orebodies. The method progresses downwards by means of blasting ore and self- } \\
\text { sustaining cave propagation of the host rock. } \\
\text { For this work, SLC is assumed suited to steep, relatively narrow orebodies with the hangingwall significantly less competent than the } \\
\text { ore. However, it is acknowledged that this is not necessarily so; considering that it is one of the more flexible and versatile mining } \\
\text { methods that can be employed successfully to thick, flat-dipping orebodies }\end{array}$ \\
\hline Vertical crater retreat & VCR & $\begin{array}{l}\text { An underground mining method for steep-dipping orebodies. The method retreats upwards by means of charging holes from a top } \\
\text { access and blasting slices off the bottom of the ore into a bottom access. }\end{array}$ \\
\hline Transverse open stoping & TOS & $\begin{array}{l}\text { An underground mining method for wide orebodies. The mining retreats from the hangingwall side to the footwall side of the orebody } \\
\text { through long blastholes drilled from a series of parallel crosscuts in the orebody. }\end{array}$ \\
\hline Longitudinal open stoping & LOS & $\begin{array}{l}\text { An underground mining method for steep-dipping, narrow orebodies in which mining retreats from the ends of defined blocks of ore } \\
\text { through long blastholes drilled from on-reef strike-parallel drifts. }\end{array}$ \\
\hline Cut and fill & C\&F & $\begin{array}{l}\text { An underground mining method that typically progresses upward from the bottom through a series of relatively narrow horizontal cuts } \\
\text { that are backfilled to form platforms for the next cut directly above. }\end{array}$ \\
\hline Drift and fill Mining & D\&F & $\begin{array}{l}\text { An underground mining method for flat-dipping, narrow orebodies that progresses through a series of drifts, each of which is backfilled } \\
\text { before the next adjacent drift is mined. }\end{array}$ \\
\hline Longwall stoping & LW & $\begin{array}{l}\text { An underground mining method for flat-dipping, narrow orebodies, in which typically long breast, updip or downdip panels are } \\
\text { advanced. Broken ore is recovered by mechanical means (scrapers or low-profile mechanized equipment). }\end{array}$ \\
\hline Room and pillar & $R \& P$ & $\begin{array}{l}\text { An underground mining method for flat-dipping, narrow orebodies that are mined through series of parallel drifts in grid fashion, leaving } \\
\text { regularly sized and spaced permanent ore pillars in situ } \\
\text { R\&P mining in wide orebodies, where the pillar strength is augmented by paste fill, is not considered an independent mining method, } \\
\text { but rather a combination of two mining methods, i.e. C\&F and R\&P. As such it is not considered in this work as a mining method. }\end{array}$ \\
\hline
\end{tabular}




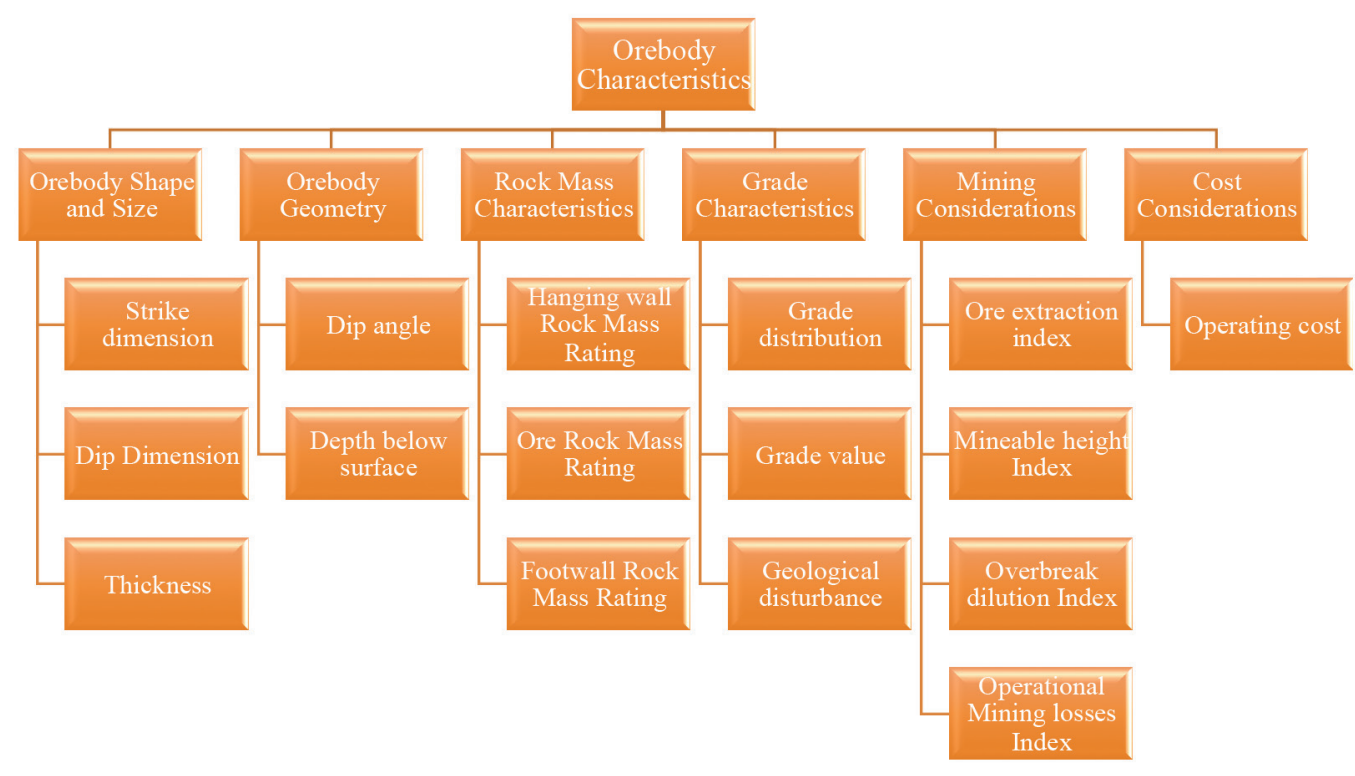

Figure 2-Orebody characteristics and considerations

The experience of mining engineers who had faced the task of mining method selection, including that of the authors, was utilized in judging the suitability of mining methods to these characteristics. All this information had been assimilated during practical applications and it culminated in the MSAHP technique.

The orebody characteristics and considerations for MSAHP are shown in Figure 2.

\section{Orebody shape and size}

\section{Massive and stratiform ore deposits}

For MSAHP, two categories of mining methods have been identified based on the overall shape of the orebody. These are massive and stratiform mining methods. Massive methods are those best suited to orebodies of which the strike length, dip length and thickness are comparable in size, or 'equidimensional'. Stratiform mining methods are those suited to orebodies of which one dimension is a fraction of the other two. Stratiform examples include the tabular orebodies of the typical South African hard-rock mines and near-vertical vein deposits in many parts of the world, including Kapan in Armenia, Goldboro Mine in Canada, and Canterfield in Australia.
In MSAHP, the distinction between a massive and stratiform orebody is made on the basis of Equation [1]:

$$
R_{D} \leq K \frac{\sqrt{D_{s} \times D_{d}}}{T h}
$$

where $R_{D}$ is the ratio of the area of the footprint to the thickness of the orebody; $D_{s}$ is the strike dimension of the orebody; $D_{d}$ is the dip dimension of the orebody; and $T_{h}$ is the orebody thickness. The orebody is suitable for massive mining operations if $R_{D}$ in Equation [1] is true, otherwise it lends itself to stratiform mining methods. For MSAHP the initial value for the constant $K$ is 3 .

In MSAHP the orebody characteristics are input in both numeric and linguistic terms. Each term is quantified by assigning a value, or weight, to it.

The weight of any given term is different depending on whether the orebody is massive or stratiform. For example, short dip and strike dimensions might be advantageous for block caving, while for the same dimensions, longwall stoping would be inappropriate.

\begin{tabular}{|c|c|c|c|c|c|c|c|c|c|}
\hline \multicolumn{10}{|c|}{$\begin{array}{l}\text { Table II } \\
\text { Quantification of orebody shape and size }\end{array}$} \\
\hline \multicolumn{10}{|c|}{ Orebody general shape } \\
\hline \multicolumn{4}{|c|}{ Strike dimension } & \multirow{2}{*}{\multicolumn{2}{|c|}{$\begin{array}{r}\text { Dip diamension } \\
\text { Weight }\end{array}$}} & \multicolumn{4}{|c|}{ Thickness } \\
\hline \multirow{2}{*}{ km } & \multirow{2}{*}{ Description } & \multicolumn{2}{|c|}{ Weight } & & & \multirow{2}{*}{ m } & \multirow[t]{2}{*}{ Description } & \multicolumn{2}{|c|}{ Weight } \\
\hline & & Massive & Stratiform & Massive & Stratiform & & & Massive & Stratiform \\
\hline 0.1 & Very short & 10 & 1 & 10 & 1 & 0 & Very thin & 1 & 100 \\
\hline 0.5 & Short & 100 & 10 & 80 & 10 & 5 & Thin & 1 & 50 \\
\hline 1 & Medium & 100 & 100 & 100 & 00 & 40 & Medium & 80 & 1 \\
\hline 3 & Long & 50 & 100 & 50 & 100 & 80 & Thick & 100 & 1 \\
\hline 5 & Very long & 50 & 100 & 50 & 100 & 500 & Very thick & 00 & 1 \\
\hline
\end{tabular}




\section{MSAHP: An approach to mining method selection}

\begin{tabular}{|c|c|c|c|c|c|c|c|}
\hline \multicolumn{8}{|c|}{ Orebody geometry } \\
\hline \multicolumn{4}{|l|}{ Dip angle } & \multicolumn{4}{|c|}{ Depth } \\
\hline \multirow{2}{*}{ Degrees } & \multirow{2}{*}{ Description } & \multicolumn{2}{|c|}{ Weight } & \multirow{2}{*}{ m } & \multirow{2}{*}{ Description } & \multicolumn{2}{|c|}{ Weight } \\
\hline & & Massive & Stratiform & & & Massive & Stratiform \\
\hline$<15$ & Flat & 100 & 100 & 0 & Very shallow & 100 & 70 \\
\hline 15 to 30 & Slightly inclined & 100 & 100 & 250 & Shallow & 80 & 100 \\
\hline 30 to 45 & Moderately inclined & 10 & 50 & 750 & Intermediate & 100 & 100 \\
\hline 45 to 60 & Steeply inclined & 50 & 100 & 2000 & Deep & 100 & 100 \\
\hline 60 to 90 & Very steeply inclined & 50 & 100 & 3000 & Very deep & 30 & 1 \\
\hline
\end{tabular}

The numerical values assigned to the terms are empirical and somewhat arbitrary; however, they should be regarded as benchmarks and unless there is substantial reason to believe that they are incorrect, changing them is inadvisable.

The quantification for orebody shape and size is shown in Table II.

\section{Orebody geometry}

The angle of dip and the depth of the orebody define the orebody geometry in MSAHP. The quantifications of descriptions for dip and depth are shown in Table III. Quantification is dependent on the shape of the orebody, whether massive or stratiform.

\section{Rock mass quality}

Unlike all the other characteristics, which pertain to the orebody only, geomechanical characteristics include the hangingwall and the footwall. In Nicholas' method the values assigned to geomechanical characteristics for the ore are added to those of the hangingwall and footwall. This results in over-emphasis of the geomechanical properties at the cost of other very (perhaps more) important parameters such as dip and thickness. In MSAHP, the importance of the geomechanical properties for the ore, hangingwall, and footwall are evaluated independently with respect to each other as well as to the other parameters, by way of pairwise comparisons.

In the early phases of studies, most geomechanical engineers will insist on classifying the rock mass quality according to at least one rock mass classification system.

The rock mass rating (RMR) system (Bieniawski, 1989) encapsulates the geomechanical properties of rock masses. It is convenient to use the quantification ranges of that system directly, for three reasons:

- It is an authoritative system that is very widely used throughout the mining industry

> It already quantifies the linguistic terms such as 'Very good', 'Poor' etc.

- It results in a universal understanding of the rock mass quality across disciplines and departments.

The quantifications used in MSAHP are listed in Table IV.

\section{Grade characteristics and geological disturbance}

The distribution and value of grade and the extent of geological disturbance influence the requirements for selectivity and flexibility of mining methods. The terms used to describe the grade characteristics and their quantifications are provided in Table V, and those for geological disturbance in Table VI.

\section{Mining considerations}

Two additional categories of characteristics were included to enhance the analyses and extend the functionality of the system. The fifth category encompasses the mining factors that are

Table IV

Quantification of rock mass characteristics

Rock mass characteristics

\begin{tabular}{|l|l|}
\hline RMR & Description \\
\hline 20 & Very poor \\
\hline 40 & Poor \\
\hline 60 & Fair \\
\hline 80 & Good \\
\hline 100 & Very good \\
\hline
\end{tabular}

Table V

Quantification of grade characteristics

Grade characteristics

\begin{tabular}{|l|l|l|}
\hline Distribution & Description & Weight \\
\hline Highly disseminated & Very low & 2 \\
\hline Disseminated & Low & 3 \\
\hline Moderately uniform & Average & 10 \\
\hline Uniform & High & 30 \\
\hline Highly uniform & Very high & 50 \\
\hline
\end{tabular}

Table VI

Quantification of geological disturbance

\begin{tabular}{|l|l|l|}
\hline \multicolumn{2}{|l|}{ Geological disturbance } \\
\hline$\%$ & Description & Weight \\
\hline 1 & Very low & 100 \\
\hline 5 & Low & 80 \\
\hline 10 & Medium & 20 \\
\hline 15 & High & 10 \\
\hline 20 & Very high & 1 \\
\hline
\end{tabular}




\section{MSAHP: An approach to mining method selection}

usually considered for a study, and the final category brings the direct mining cost per ton of ore produced into consideration. These factors are consequential to the choice of mining method and are not selection criteria, but benchmark values for them can be useful to discriminate between mining methods when it is difficult to do so based on the orebody characteristics alone.

\section{Extraction index}

This is a measure of the ratio of the ore allowed to be broken to the total available ore in reserve. The sterilized ore serves as stability pillars.

The terms used to describe the extraction index and their quantifications are presented in Table VII.

\section{Mineable height index}

The mineable height is the vertical height of a production stope or block of economically mineable ore. It may be restricted because of grade considerations, geomechanical constraints, or practical mining considerations, such as the maximum reach to which equipment can be extended.

The terms used to describe the mineable height index and its quantifications are presented in Table VIII.

\section{Overbreak dilution index}

The overbreak dilution index measures the lowering of the grade of the broken ore because of the introduction of sub-economic material.

The terms used to describe the overbreak dilution index and their quantifications are presented in Table IX.

\section{Operational mining losses index}

This index is a measure of the broken ore that is left underground and is irrecoverable due to geometric, logistical, or other operational-related mining constraints.

\begin{tabular}{|l|l|l|l|}
\hline \multicolumn{2}{|l|}{$\begin{array}{l}\text { Table VII } \\
\text { Quantification of extraction index }\end{array}$} \\
\hline \multicolumn{3}{|l|}{ Extraction index } \\
\hline \multirow{2}{*}{$\%$} & \multirow{2}{*}{ Description } & \multicolumn{2}{|c|}{ Weight } \\
\cline { 3 - 4 } & & Massive & Stratiform \\
\hline $50 \%$ & Very low & 50 & 50 \\
\hline $60 \%$ & Low & 60 & 60 \\
\hline $75 \%$ & Average & 80 & 80 \\
\hline $80 \%$ & High & 90 & 90 \\
\hline $100 \%$ & Very high & 100 & 100 \\
\hline
\end{tabular}

\begin{tabular}{|l|l|l|l|}
\hline \multicolumn{2}{|l|}{ Table VIII } \\
Quantification of mineable height index \\
\hline \multicolumn{2}{|l|}{ Mineable height index } \\
\hline \multirow{2}{*}{$\mathbf{m}$} & Description & \multicolumn{2}{|c|}{ Weight } \\
\cline { 3 - 4 } & & Massive & Stratiform \\
\hline 1 & Very low & 1 & 100 \\
\hline 6 & Low & 10 & 80 \\
\hline 15 & Med & 20 & 75 \\
\hline 30 & High & 80 & 60 \\
\hline 100 & Very high & 100 & 50 \\
\hline
\end{tabular}

Table IX

Quantification of overbreak dilution index

Overbreak dilution index

\begin{tabular}{|l|l|l|}
\hline $1 \%$ & Very low & 100 \\
\hline $3 \%$ & Low & 50 \\
\hline $5 \%$ & Med & 10 \\
\hline $15 \%$ & High & 5 \\
\hline $20 \%$ & Very high & 1 \\
\hline
\end{tabular}

Table $X$

Quantification of operational mining losses index

Operational mining losses index

\begin{tabular}{|l|l|l|}
\hline$\%$ & Description & Weight \\
\hline 1 & Very low & 100 \\
\hline 3 & Low & 80 \\
\hline 5 & Med & 40 \\
\hline 15 & High & 10 \\
\hline 20 & Very high & 1 \\
\hline
\end{tabular}

The terms used to describe the operational mining losses index and their quantifications are presented in Table X.

\section{Production cost per ton mined}

A final consideration is the cost of mining at steady state. For the MSAHP tool, the direct cost per ton mined was considered to be the best differentiator between mining methods when financial implications are taken into account. Capital and processing costs are influenced by factors other than the mining method and are not directly comparable between one mining method and another, or even the same mining method among different mines.

The mining costs are semi-hard-coded into MSAHP. This factor can be easily adjusted at any time to reflect the most up-todate knowledge.

\section{AHP criteria}

MSAHP deviates from conventional AHP analyses concerned with mining method selection. In the reviewed studies, the mining methods are assessed in pairwise comparison with respect to the criteria. The mining methods would typically be compared to each other with reference to, for example, orebody thickness, and the following questions would be asked:

- Is cut and fill mining more or less suitable to orebody thickness than drift and fill mining?

$>$ How much more or less suitable is it? The difficulty presented by this type of question is that the reference point is not fixed: one mining method might be more suitable to a thick portion of the orebody while another may be more suitable to a thin portion. Instead of this scheme, MSAHP compares orebody characteristics to each other with reference to each mining method. The questions that may be asked in this scheme are as follows:

> With reference to cut and fill, is a thick orebody more or less advantageous than a long strike dimension?

- How much more advantageous is it? 
MSAHP: An approach to mining method selection

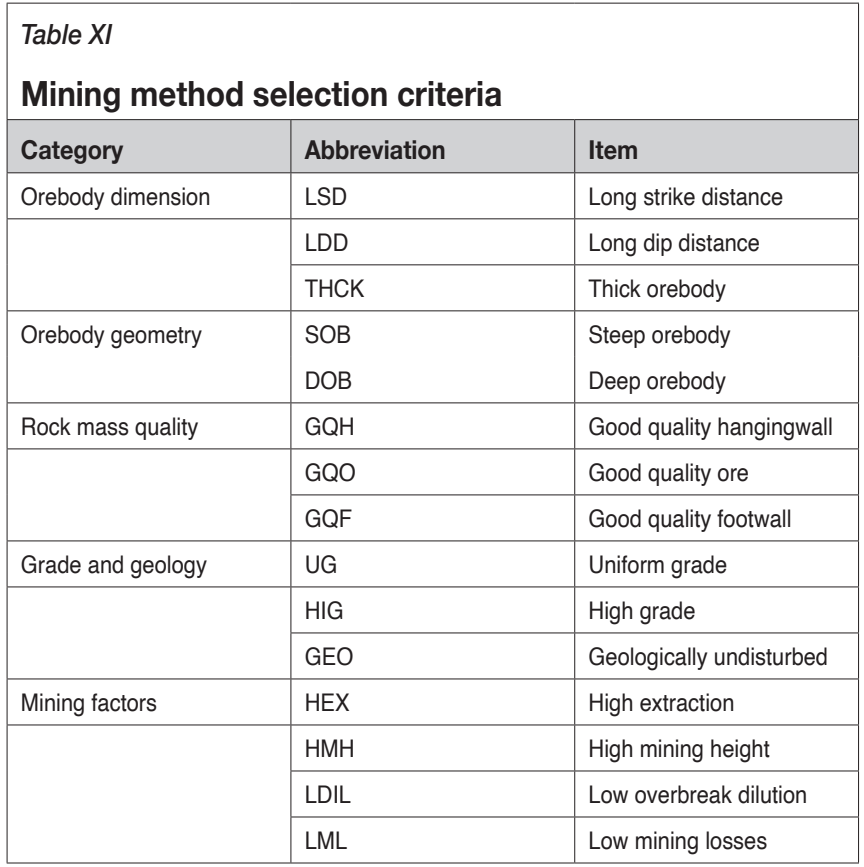

This approach greatly simplifies the cognitive processes while carrying out the pairwise comparisons.

In MSAHP, the criteria are grouped into categories and pairwise comparisons are made between criteria that are logically related. This obviates the need for comparing seemingly incomparable items; for example, the dip of the orebody and the grade of the ore. The mining method selection criteria used for the pairwise comparisons are given in Table XI.

\section{Pairwise comparison}

The comparison matrices were populated with judgements based on case studies, the expert opinion of mining engineers who have considerable experience in mining method selection, and published literature, most notably Hustrulid and Bullock (2001) and Brady and Brown (2006).

To explain the pairwise comparison process, sets of comparison matrices for three mining methods are shown in Figure 3: open pit mining (OPM), block cave mining (BCM), and sublevel caving (SLC). The matrices compare, in pairwise fashion, the orebody dimensions: long strike distance (LSD), long dip distance (LDD), and thick orebody (THCK). The left-hand matrix of each set is the comparison matrix and the one on the right is the priority matrix in which the relative priorities of the items are calculated. Balt (2016) deals comprehensively with the AHP methodology and the application of Excel ${ }^{\mathrm{TM}}$ to the process.

It should be noted at this point that the criteria are specific; for example, 'long strike distance' and 'steep orebody'. The reason for this is to introduce relatively fixed concepts in respect of which the mining methods can be compared. For example, comparing LOS and LWS with respect to dip without qualification leads to a question like: 'Is LOS more or less suited to the dip than LWS?', which cannot be answered. By qualifying dip as 'steep', the question becomes: 'Is LOS more or less suited to a steep dip than LWS?', which has a definitive answer.

Since OPM, LSD, and LDD are deemed equally important, the number 1 appears in the row/column intersections. THCK is judged to be five times more important for the consideration of

OPM than both LSD and LDD. This is signified by the fraction $1 / 5$ in (LSD, THCK) and (LDD, THCK). In AHP, the convention is to compare the item in the leftmost column relative to the item in the topmost row. If LSD were to be judged five times more important than THCK, the value in (LSD, THCK) would have been 5 .

As another example, consider SLC. For this mining method LDD is judged three times more important than LDD and the latter is, in turn, three times more important than THCK.

The priorities in the column PV gives an indication of the weight of each of the items with respect to the mining method. For both OPM (71\%) as well as BCM (78\%), the thickness is of much greater significance than the other two dimensions, while for SLC, LSD (59\%) is significantly more important than the other two dimensions and LDD (29\%) weighs more than double THCK $(14 \%)$. Calculation of these priorities is beyond the subject matter covered in this paper. For detailed explanations, the reader is referred to Balt (2016).

\section{MSAHP methodology}

MSAHP consists of two streams of workflow as illustrated in Figure 4. The first stream is concerned with the actual orebody characteristics which are inputs to the analysis by the engineers concerned with the study, based on the available knowledge. The second deals with the ideal attributes for all the mining methods and has been derived from case studies, expert opinions, and the literature. The two streams come together in the synthesis phase,

\begin{tabular}{|c|c|c|c|c|c|c|c|c|c|}
\hline 4 & & B & c & D & E & $\mathrm{F}$ & G & H & 1 \\
\hline 1 & MMthd & \multicolumn{8}{|c|}{ Ore body Dimensions } \\
\hline 2 & \multirow{4}{*}{ OPM } & & LSD & LDD & THCK & LSD & LDD & THCK & PV \\
\hline 3 & & LSD & 1 & 1 & $1 / 5$ & 0.14 & 0.14 & 0.14 & $14 \%$ \\
\hline 4 & & LDD & 1 & 1 & $1 / 5$ & 0.14 & 0.14 & 0.14 & $14 \%$ \\
\hline 5 & & THCK & 5 & 5 & 1 & 0.71 & 0.71 & 0.71 & $71 \%$ \\
\hline 6 & & & 7 & 7 & $12 / 5$ & & & & \\
\hline \multicolumn{10}{|l|}{7} \\
\hline \multicolumn{10}{|l|}{8} \\
\hline 9 & \multirow{4}{*}{ BCM } & & LSD & LDD & THCK & LSD & LDD & THCK & PV \\
\hline 10 & & LSD & 1 & 1 & $1 / 7$ & 0.11 & 0.11 & 0.11 & $11 \%$ \\
\hline 11 & & LDD & 1 & 1 & $1 / 7$ & 0.11 & 0.11 & 0.11 & $11 \%$ \\
\hline 12 & & THCK & 7 & 7 & 1 & 0.78 & 0.78 & 0.78 & $78 \%$ \\
\hline 13 & & & 9 & 9 & $12 / 7$ & & & & \\
\hline 14 & & & & & & & & & \\
\hline 15 & & & & & & & & & \\
\hline 16 & \multirow{4}{*}{ SLC } & SLC & LSD & LDD & THCK & LSD & LDD & THCK & PV \\
\hline 17 & & LSD & 1 & 3 & 3 & 0.60 & 0.69 & 0.43 & $57 \%$ \\
\hline 18 & & LDD & $1 / 3$ & 1 & 3 & 0.20 & 0.23 & 0.43 & $29 \%$ \\
\hline 19 & & THCK & $1 / 3$ & $1 / 3$ & 1 & 0.20 & 0.08 & 0.14 & $14 \%$ \\
\hline 20 & & & $12 / 3$ & $41 / 3$ & 7 & & & & \\
\hline 21 & & & & & & & & & \\
\hline
\end{tabular}

Figure 3-Snip of pairwise comparison tables showing the matrices of orebody dimensions for three mining methods

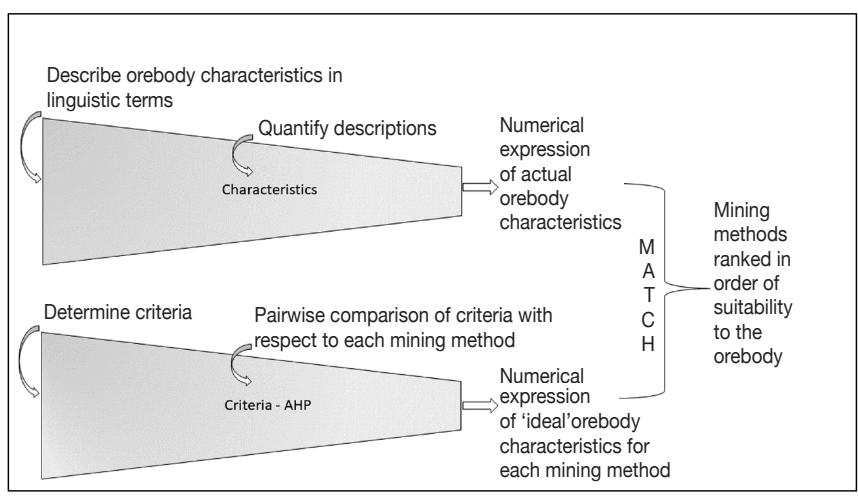

Figure 4-Outline of MSAHP workflow 


\section{MSAHP: An approach to mining method selection}

where the actual orebody characteristics are matched to the ideal attributes for each mining method. The mining methods are then ranked according to the best fit of the orebody characteristics to the ideal attributes for each mining method.

\section{Orebody characterization}

The orebody characteristics considered for MSAHP were given in Figure 2. The characteristics are grouped into four logical categories: namely the orebody dimensions, the orebody geometry, the rock mass ratings of the hangingwall, ore, and footwall, and the grade characteristics. These are the characteristics that are provided by nature and are not under human control.

\section{Mining factors and production costs}

The mining factors -extraction, mining height, overbreak dilution, and mining losses - are under the control of the mining engineer, subject to constraints imposed by the mining method. As such, these factors are not selection criteria per se and are used in MSAHP mainly to test the robustness of the mining method ranking order in the face of varying constraining scenarios.

When the suitability of mining methods is so evenly matched that a clear decision is not forthcoming, the production cost per ton mined can often be the deciding factor. For this reason, as well as to estimate the effect of production cost on the ranking of mining methods, production cost per ton mined was included as a criterion.

\section{Synthesis}

The process is synthesised by finding the product of the priority vector for each criterion with respect to every mining method and the score obtained through the evaluation of the actual orebody characteristics. The final score for each mining method is achieved by summing the products.

Figure 5 is an impression of a typical scenario where the given orebody characteristics have been entered and quantified into a score. The score for each of the orebody characteristics is multiplied by the priority vector for each of the criteria shown in Figure 6. This represents the ideal orebody for each mining method. The results of this multiplication are shown in Figure 7. By way of illustration, consider the dip angle. In the evaluation of the actual orebody characteristics, a dip of $35^{\circ}$ is described as 'moderately inclined' and it results in a score of 50. In Figure 6, the priority of dip for TOS is $83 \%$.

The product of these two values is 42 , the highlighted value in Figure 7 . The values for the criteria are finally summed to produce a total measure of the suitability of each mining method to the actual orebody configuration, and the mining methods are then ranked according to the scores from high to low, as shown in Figure 8.

When the analysis reaches this stage, the objectives of the analysis have been achieved. However, it is at this juncture that different scenarios can be evaluated by varying the numbers of the 'controllable' variables - that is, the mining factors and the cost. For example: '... what if a low dilution index is a requirement, would the ranking change?'

\section{Benefit to cost ratio}

Benefit-to-cost ratio has been built into MSAHP to make the analysis more complete. This does not allow MSAHP to be used as a substitute for appropriate economic modelling, but merely

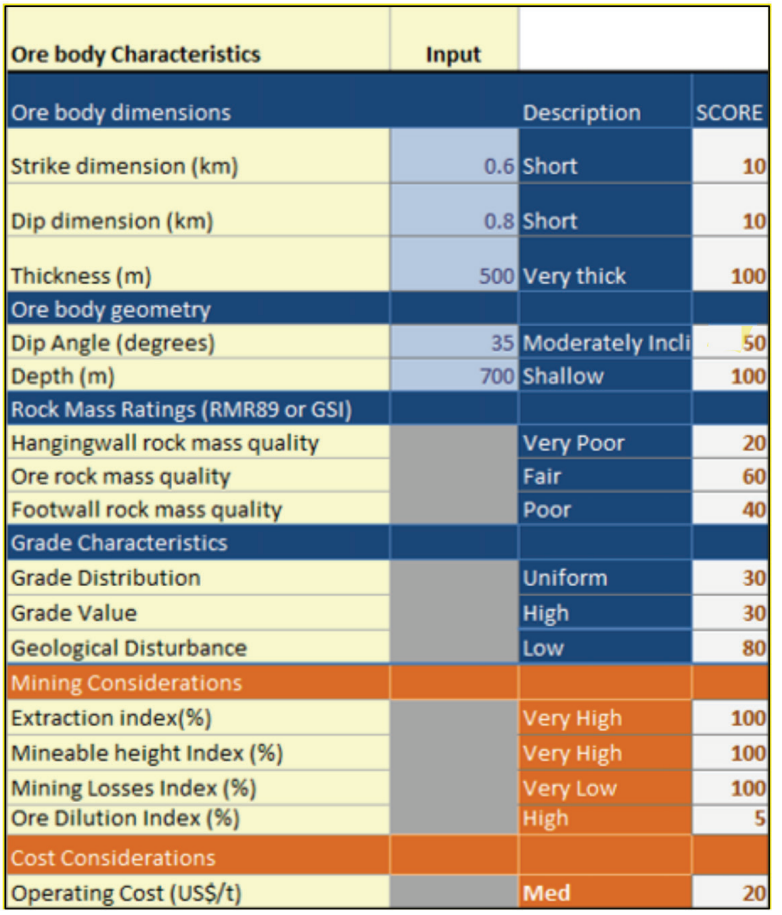

Figure 5-Scores for actual orebody characteristics derived from available information

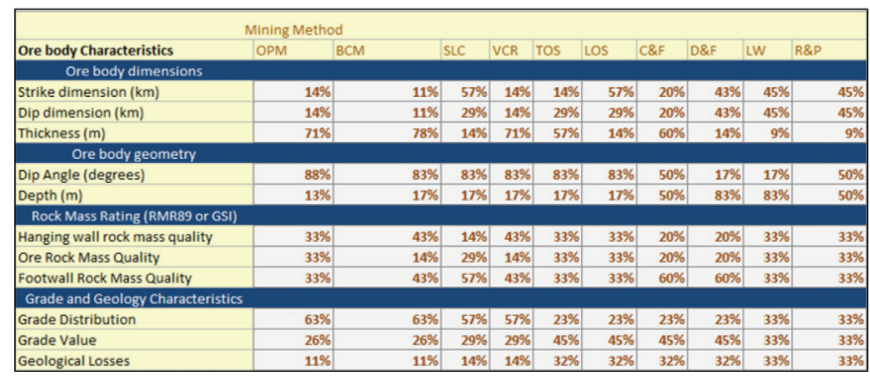

Figure 6-Priority vectors for criteria with respect to mining methods

\begin{tabular}{|c|c|c|c|c|c|c|c|c|c|}
\hline \multicolumn{10}{|c|}{ Ranking Score } \\
\hline OPM & $\mathrm{BCM}$ & SLC & VCR & TOS & LOS & C\&F & D\&F & LW & $R \& P$ \\
\hline 74 & 80 & 23 & 74 & 62 & 23 & 64 & 23 & 18 & 18 \\
\hline 1.4 & 1.1 & 5.7 & 1.4 & 1.4 & 5.7 & 2.0 & 4.3 & 4.5 & 4.5 \\
\hline 1.4 & 1.1 & 2.9 & 1.4 & 2.9 & 2.9 & 2.0 & 4.3 & 4.5 & 4.5 \\
\hline 71.4 & 77.8 & 14.0 & 71.4 & 57.4 & 14.0 & 60.0 & 14.3 & 9.1 & 9.1 \\
\hline 56 & 58 & 58 & 58 & 58 & 58 & 75 & 92 & 92 & 75 \\
\hline 44 & 42 & 42 & 42 & 42 & 42 & 25 & 8 & 8 & 25 \\
\hline 13 & 17 & 17 & 17 & 17 & 17 & 50 & 83 & 83 & 50 \\
\hline 40 & 34 & 43 & 34 & 40 & 40 & 40 & 40 & 40 & 40 \\
\hline 7 & 9 & 3 & 9 & 7 & 7 & 4 & 4 & 7 & 7 \\
\hline 20 & 9 & 17 & \begin{tabular}{l|l}
9 \\
\end{tabular} & 20 & 20 & 12 & 12 & 20 & 20 \\
\hline 13 & 17 & 23 & 17 & 13 & 13 & 24 & 24 & 13 & 13 \\
\hline 89 & 89 & 80 & 80 & 32 & 32 & 32 & 32 & 47 & 47 \\
\hline 19 & 19 & 17 & 17 & 7 & 7 & 7 & 7 & 10 & 10 \\
\hline 19 & 19 & 17 & 17 & 7 & 7 & 7 & 7 & 10 & 10 \\
\hline 51 & 51 & 46 & 46 & 18 & 18 & 18 & 18 & 27 & 27 \\
\hline 259 & 261 & 204 & 247 & 192 & 152 & 211 & 186 & 197 & 180 \\
\hline 76 & 53 & 53 & 53 & 89 & 88 & 76 & 88 & 84 & 84 \\
\hline 25 & 17 & 17 & 17 & 10 & 28 & 25 & 38 & 39 & 39 \\
\hline 25 & 17 & 17 & 17 & 42 & 39 & 25 & 13 & 6 & 6 \\
\hline 25 & 17 & 17 & 17 & 36 & 20 & 25 & 38 & 39 & 39 \\
\hline 1 & 3 & 3 & 3 & 1 & 1 & 1 & 1 & 1 & 1 \\
\hline 0 & 2 & 2 & 3 & 2 & 2 & 3 & 3 & 2 & 2 \\
\hline 0 & 2 & 2 & 3 & 2 & 2 & 3 & 3 & 2 & 2 \\
\hline
\end{tabular}

Figure 7-Synthesised evaluation 


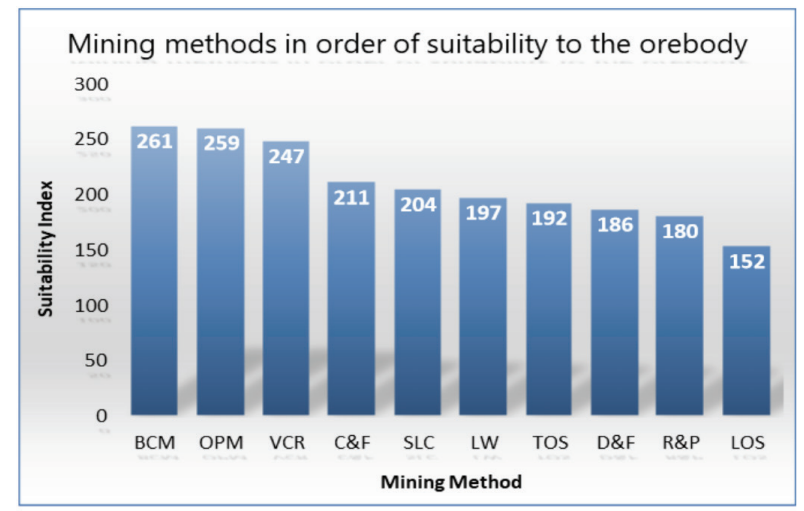

Figure 8-Final scores and rankings of mining methods in order of their suitability to the actual orebody characteristics

allows for an indication of the effect that costs might have on the selection. This is done by way of determining the benefit/cost ratio. The orebody characteristics are taken as the benefit and the mining and cost per ton considerations constitute the cost. The mining cost per ton is built into MSAHP as a set of userconfigurable variables. A graph like that in Figure 9 is produced. Note that for this analysis, the ranking order has changed, with SLC and C\&F swapping places. The mining cost considered for this example is given in Table XII.

\section{Disqualification of mining methods}

All mining methods are constrained by some or other aspect of the orebody geometry. For example, open pit mining at depths greater than about $600 \mathrm{~m}$ is very rare and will be considered only under extraordinary circumstances. A feature of MSAHP is that it allows disqualification of mining methods after the ranking order has been established. With the feature disabled, all the mining methods are shown (see Figure 8); when it is enabled only the qualifying suitable mining methods are presented for consideration, as shown in Figure 10, which is based on the same data as Figure 8.

Since the final scores for the disqualified mining methods are simply set to zero, the ranking order of the qualifying mining methods is maintained.

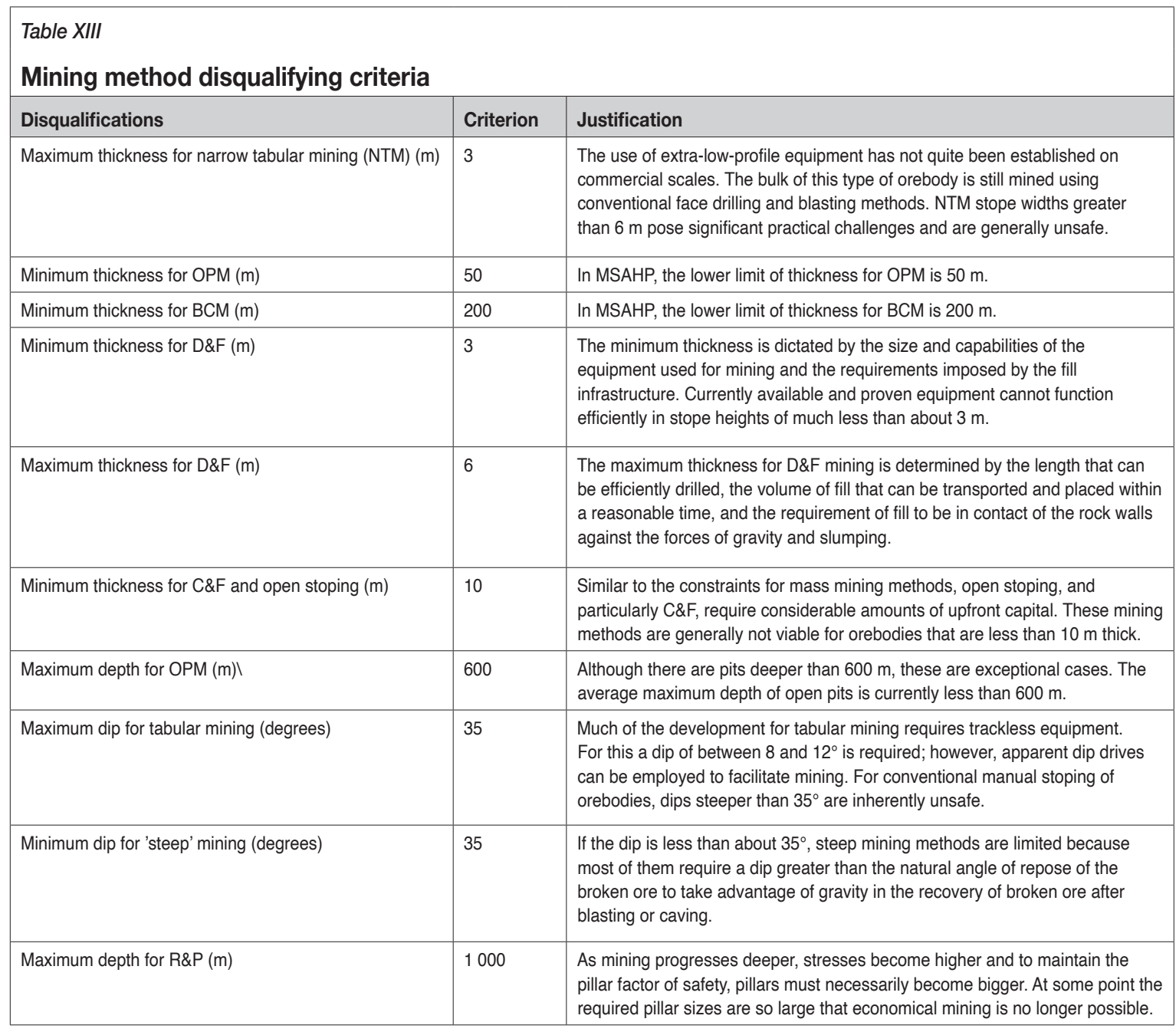




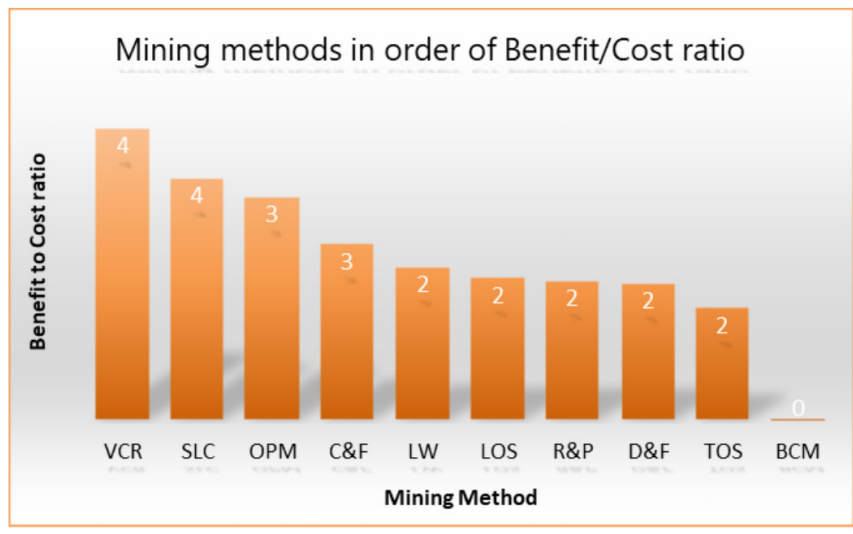

Figure 9-Benefit to cost ratio

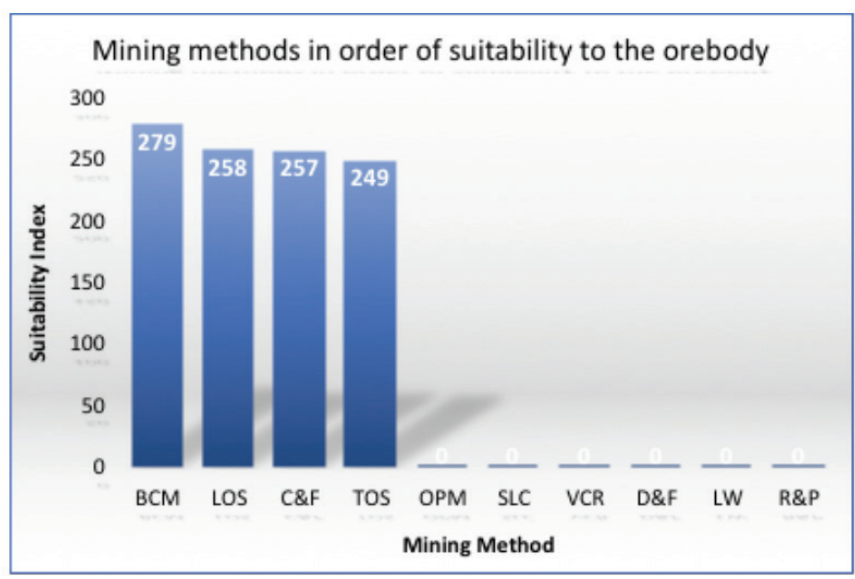

Figure 10-Rankings after disqualification

The disqualifying criteria are shown in Table XIII.

One additional disqualification may be imposed by the user: The impact of mining on the environment is a very serious consideration and there are areas where the Earth's surface may not be disturbed. In these cases, mining methods that have the potential to cause substantial displacement, such as BCM and SLC, must be disqualified even if they are the preferred mining methods.

\section{Conclusions}

Mining method selection, the most fundamental aspect of mine design, is also inherently one of the most difficult because the selection must take place when information is at a minimum. Several methods and techniques have been developed, and without doubt will continue to be developed to help with the selection process. The AHP is powerful and computationally relatively simple, although it does require considerable time and study to really understand it. Time is almost never an abundant resource, and so designers will always fall back on what is easiest and familiar and will give quick results that are at least approximately correct, unless there is something simpler that they can trust. This paper discussed a transparent, user-friendly technique which simplifies mining method selection even though it is driven by a powerful and proven decision-making process.
The case studies demonstrate that the technique, although by no means claimed to be flawless, is robust enough to give adequate guidance to the mining method selection process.

The case studies show that MASHP is a practical and implementable tool for mining method selection, even in the face of sparse data.

\section{Case studies}

Many case studies were back-analysed. The input information in all cases was sourced from publications and the internet. It is certain that for pre-feasibility and feasibility study phases, considerably more information is normally available; nevertheless, in all the case studies, the mining methods in the source documents were in the top four of the MSAHP-ranked mining methods.

\section{References}

Ataei, M., Jamshidi, M., Sereshi, F., and Jalali, S.M.E. 2008. Mining method selection by AHP approach. Journal of the Southern African Institute of Mining and Metallurgy, vol. 108. pp. 741-749.

BALT, K.D. 2016. A methodology for implementingt he analytic hierarchy process to decision making in mining. Worley, Johannesburg.

BIENIAWSKI, Z.T. 1989. Engineering Rock Mass Classifications: A Complete Manual for Engineers and Geologists in Mining, Civil, and Petroleum Engineering. 1st edn. Wiley-Interscience, New York.

Brady, B.H.G. and Brown, E.T. 2006. Rock Mechanics for Underground Mining, 3rd edn. (reprinted with corrections. Springer, Dordrecht.

Hustrulid, W.A. and Bullock, R.C. (eds). 2001. Underground mining methods: engineering fundamentals and international case studies. Society for Mining, Metallurgy, and Exploration, Littleton, co.

KLuge, P. and MaLAN, D.F. 2011. The application of the analytical hierarchical process in complex mining engineering design problems. Journal of the Southern African Institute of Mining and Metallurgy, vol. 111. pp. 847-855.

Musingwinl, C. and MinNitT, R.C.A. 2008. Ranking the efficiency of selected platinum mining methods using the analytic hierarchy process (AHP). Proceedings of the Third International Platinum Conference: 'Platinum in Transformation'. Southern African Institute of Mining and Metallurgy, Johannesburg. pp. 319-326.

Nicholas, D.E. 1981. Method selection - A numerical approach. https://www. cnitucson.com/publications/1981_Nicholas_436-Method\%20Selection\%20-\%20 A\%20Numerical\%20Approach\%201981.pdf.

SAATY, T.L. 2008. Decision making with the analytic hierarchy process. International Journal of Services Sciences. vol. 1. pp. 83-98.

YavuZ, M., IPHAR, M., and Once, G. 2008. The optimum support design selection by using AHP method for the main haulage road in WLC Tuncbilek colliery. Tunnelling and Underground Space Technology, vol. 23. pp. 111-119. https:// doi.org/10.1016/j.tust.2007.02.001 